\title{
Urgences
}

\section{La matière pour l'objet}

\section{Vianney Gallant}

Numéro 13, mars 1986

\section{Éclats d'atelier}

URI : https://id.erudit.org/iderudit/025199ar

DOI : https://doi.org/10.7202/025199ar

Aller au sommaire du numéro

\section{Éditeur(s)}

Urgences

\section{ISSN}

0226-9554 (imprimé)

1927-3924 (numérique)

Découvrir la revue

\section{Citer ce document}

Gallant, V. (1986). La matière pour l'objet. Urgences, (13), 15-17. https://doi.org/10.7202/025199ar d'utilisation que vous pouvez consulter en ligne.

https://apropos.erudit.org/fr/usagers/politique-dutilisation/ 


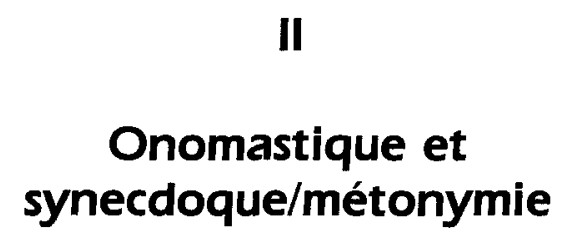




\section{Postulats: onomastique et synecdoque/métonymie}

Écrire un texte à incidence synecdochique et métonymique où, trois fois au moins, s'inscrivent, par initialisation (acrostiche), calembour/à-peu-près, paragramme ou procédé roussellien, le prénom et/ou le nom du scripteur.

Synecdoque, métonymie, acrostiche, calembour, à-peu-près - voir Bernard Dupriez: Gradus, coll. "10/18", 1370, Paris, UGE, 1980, pages correspondantes.

Paragramme - voir Alain Duchesne et Thierry Leguay: Petite fabrique de littérature, coll. "Textes et contextes", Paris, Magnard, 1984, p. 181 et ss.

Procédé roussellien - voir Raymond Roussel: Comment jai écrit certains de mes livres, Paris, Pauvert. 1963, p. 9 et ss.; voir aussi Jean Ricardou: Pour une théorie du nouveau roman, coll. "Tel Quel", Paris, Seuil, 1971, p. 91 et ss. 


\section{LA MATIÈRE POUR L'OBJET Vianney Gallant}

Véritablement parti pour le doute, né le... Comme s'il y avait une tête et une queue à mon séjour ici-bas; Joseph au ber, je me vis prostinstitué, la lettre pour matière en un milieu aqueux.

- Tu te détournes d'abjecte manière via l'encre. Tu te dis séculier alors que dans ton regard pluriel je me sens unique, sacré.

- Moi je te dis que tu t'en sacres. J'écris pour me donner un genre et une ombre.

- Ah mon espèce! Quelle phume tu fais! Tu t'abstrais pour te concrétiser, propre comme un lac acide. Au fait, tu lis tes classiques? Rien ne me régale plus en toi. Rien ne t'arrive sans mon étau Némésis.

- Quelle protéenne affectation! Castrastrophe!

- C'est un gag!

Galvanisée de trop lentes vibrations, tu te glanes en vain. Rien ne t'arrive. Pourtant, tu lui causes pour l'effet.

- Je l'ai fait pour la cause.

- Moi j'en vins à voyager jusqu'à dix lieues pour la chose.

- Tu n'aurais eu, mon grand timbré, qu'à me roucouler des xxx au bas de tes labours de novembre.

- Je sais que tu serais repartie quand même, sij'ose, phtisique dans le moral, offrir ton objet propre à quelque Jules pour qu'il t'apporte la guérison par le va-et-vient du leitmotiv. 